\title{
A Review Committee's Guide for Evaluating Qualitative Proposals
}

\author{
Janice M. Morse
}

Although they complain that qualitative proposals are not reviewed fairly when funding agencies use quantitative criteria, qualitative researchers have failed the system by not developing alternative criteria for the evaluation of qualitative proposals. In this article, the author corrects this deficit by presenting criteria to assess the relevance, rigor, and feasibility of qualitative research. These criteria are not a checklist but rather a series of questions that can aid a reviewer, adept in qualitative methods, to comprehensively evaluate and defend qualitative research.

Keywords: proposal evaluation; qualitative research; standards

E valuation of qualitative research proposals by review committees more accustomed to reviewing quantitative proposals, is a catch-22 situation. Qualitative methods are used when little is known about a topic, when the research context is poorly understood, when the boundaries of the domain are ill-defined, when the phenomenon is not quantifiable, when the nature of the problem is murky, or when the investigator suspects that the status quo is poorly conceived and the topic needs to be reexamined (Morse, 1991a). It is important to note that qualitative researchers are unable to prepare a proposal that is precise, detailed, and contractual-as expected by funding agencies-for the qualitative investigators do not have the information to prepare such a proposal. In fact, the reason they are proposing to do the research is to acquire such information. Thus, quantitative criteria, focused on evaluating the preciseness of the research design and the probability of achieving the projected results, cannot be used for qualitative proposals, yet an alternate model for evaluation for funding qualitative inquiry does not exist. ${ }^{1}$

Because the criteria developed for the evaluation of quantitative proposals (i.e., ones whose authors can provide concrete details) are also used for all proposals (including qualitative), qualitative proposals often have a very low rate of approval and are unlikely to be funded. Compounding this problem is the fact that qualitative expertise is often lacking on review committees (Munhall, 2001), consisting of 1 or 2 members among a membership of 1 to 5 to 20 - a distinct disadvantage when a grant total score is averaged from the entire committee. ${ }^{2,3}$ Thus, in addition to inappropriate criteria being used to evaluate qualitative proposals, there is only a faint voice arguing for, explaining, and interpreting qualitative assumptions to the funding committee. ${ }^{4}$

AUTHOR'S NOTE: The author is sponsored by CIHR Scientist and AHFMR Health Scholar awards.

QUALITATIVE HEALTH RESEARCH, Vol. 13 No. 6, July 2003 833-851

DOI: $10.1177 / 1049732303255367$

(C) 2003 Sage Publications 
In this article, I delineate criteria that could be used by grant review committees to evaluate qualitative proposals according to the dimensions of relevance, rigor, and feasibility. I then discuss the evaluation of mixed-methods proposals-proposals with a research design that uses both qualitative and quantitative methods.

\section{WHAT IS A QUALITATIVE PROPOSAL?}

Qualitative research refers to a myriad of methods, ranging from the well described and prescriptive (such as those using semistructured interviews) to the most unstructured, exploratory phenomenological methods, to methods that investigate processes over time and multiple sites. Qualitative inquiry may also be represented in mixed- or multiple-methods designs, in which one or more qualitative strategies are used in one project, or when several methods-either all qualitative or all quantitative-are combined within one research program. Regardless of these variations, one grant application is used, so that qualitative applications often address broad and complex problems rather than the concise hypotheses found in quantitative applications. ${ }^{5}$

\section{WHY IS THIS IMPORTANT?}

If granting agencies use criteria that are broad enough to encompass all proposals, regardless of the approaches used, then the criteria are not specific enough to be used as standards or to give guidance to the reviewers. If the criteria are too specific, then they are not appropriate for all types of research. In particular, they cannot be used for the different assumptions held in the qualitative and the quantitative paradigms. If more specific criteria are used, they tend to be derived from quantitative research (which at this time is still mainstream research, particularly in medicine). Consequently, qualitative proposals, which cannot meet those criteria, are being rejected or are receiving a lower priority score than they should be awarded. Qualitative proposals, therefore, are being denied for inappropriate and invalid reasons. Without adequate funding to expedite inquiry, qualitative research remains a smallscale endeavor with reduced researcher resources and productivity. Of concern, qualitative research is subsequently poorly valued in university communities, where researcher prestige is given according to the number of research dollars obtained, not by the worthiness of the completed research and the impact it has on the discipline.

\section{COMMON MYTHS INHERENT IN QUALITATIVE REVIEWS}

In my experience serving on grant review panels in the United States and Canada, and as an external reviewer for granting agencies in Australia, New Zealand, the United Kingdom, South Africa, and the Netherlands, I have observed that several prevailing myths interfere with the evaluation process and act as barriers to approval. First is the notion that qualitative inquiry is simplistic and simple: It produces obvious results-things that, as one reviewer claimed, "even my mother knows," or that anyone with counseling skills can do. The rationale behind these 
beliefs perhaps comes from the source of raw data (i.e., conversations and observations) and a poor understanding of the analytic processes of qualitative inquiry. The argument can be summarized in this way: If a researcher "talks to folks" and somehow synthesizes those opinions or comments, then, ultimately, the researcher has only a summary of those biased and subjective lay opinions. This perspective reveals little understanding of the nature of implicit meaning, of the ways of identifying and explicating implicit assumptions, and of the ways in which a researcher can bring to the fore beliefs and values of which even those who are members of the culture are unaware. The perspective that qualitative research is simple and easy also reveals limited knowledge of the roles of theory and of abstraction in qualitative inquiry, of generalizability, and of the processes involved in constructing qualitatively derived theory. Such challenges to validity and the view that qualitative inquiry does not produce significant and useful results are nonsense.

The second notion that interferes with a fair review of qualitative inquiry is that the research is inexpensive to conduct (Morse, 2002). Field-workers have brought this on themselves by continuing to do qualitative research on a shoestring, often self-funding their research, stating "All I need is a pencil, a notebook, and a bus ticket." In actuality, qualitative inquiry, if done well, can be very expensive. Computer data analyses demand that all members of the team have their own computers, and digital video equipment and audiorecording devices are now commonly used in all major methods. Such a toolbox is not inexpensive. Detailed analysis, even computer facilitated, is slow and, therefore, costly in staff time. Adequate sampling, to ensure saturation and adequate scope of the project, is extremely costly in the sheer volume of data produced for analysis. Finally, teamwork, although potentially shortening the project, is costly in salaries. The technological requirements of qualitative projects mean that universities must provide qualitative laboratories, for qualitative analysis has outgrown individual professors' offices or home basements. In short, excellent qualitative research is at least as expensive as quantitative survey research and is usually more costly.

\section{REVIEW COMMITTEE PROCESSES}

Most granting agencies have reviewers' guidelines that include instructions for the format of the written review. These can be as broad as section headings that will aid in the presentation of the written review and enable standardization for the reviews, and will ensure that the reviews are comprehensive. Some organizations will have the committee chair or a staff person compile and summarize all of the reviewers' comments; other will simply send the originals to the researchers. ${ }^{6}$ Most agencies "blind" the reviewer from the researcher-although the researcher will be able to obtain a list of committee members, they will not know which members reviewed their proposal.

I present the review guidelines below not as a checklist but, rather, as questions to focus the reviewer's attention on aspects of a proposal for consideration and comment. Whereas a checklist format usually enables a reviewer to determine the presence or absence of certain features (implying that absence is a weakness), the question format will enable the reviewer to make an informed decision about the quality of the proposed research. I am assuming reviewer competence-that is, the review will be conducted by individuals with enough qualitative knowledge and 
experience to make informed decisions about the adequacy of the design and the abilities of the applicant. ${ }^{7}$ Furthermore, I assume that the reviewers will have the wisdom to recognize that rather than a promise of a product, the qualitative research proposal is just that - a proposed way to proceed in exploring the problem. I also assume that the reviewers (and granting officers overseeing the project) will recognize the dictum "More bad data do not make good data," so the proposal should have enough latitude that if a strategy is not working (and a researcher is not obtaining the type of data needed for analysis), the researcher can modify data collection strategies. Qualitative research cannot be designed as precisely as experimental designs are, and, once in the field, it is essential that the investigator have the freedom to correct design issues if necessary. Qualitative researchers have even changed the questions asked if, once fieldwork commences, the questions originally proposed appear misguided or off base.

The primary reviewer has an important role in the presentation of the proposal to the committee that significantly influences the score that the proposal receives, its ranking, and whether it is eventually funded. The tone of the review, particularly that of the primary reviewer, can set the tone for the whole review, and the enthusiasm expressed for the project sets the stage for the receptivity of the committee to the project and, ultimately, how well or how poorly the proposal is scored. It is unlikely that many of the reviewers will have qualitative expertise, and only a few members of the review committee might be content experts. The odds that the reviewers will be versed in both the content and the method are very low. Thus, a reviewer has an important interpretive role, to present the study with enthusiasm or with guarded criticism, carefully endorsing the strengths of the proposal or pointing out weaknesses and the seriousness of these pitfalls.

Occasionally, questions about qualitative research will be asked of the reviewer by those on the review committee who have little understanding of the methods or even of the qualitative paradigm. It is unrealistic to expect that the applicant prepare a reasonably sophisticated proposal for a naive review committee and, on the other hand, probably unwise for the applicant to write an unsophisticated, simplistic application, for it might backfire and the applicant appear as a neophyte, unsophisticated and inexperienced. The reviewers who are presenting the proposal must therefore be able to address committee questions on the basics of qualitative inquiry, assuring the committee of the strengths and weaknesses of the project, thereby shepherding the proposal through the committee, as is the practice with proposals using other methods. However, within the space allotted and following the guidelines, the onus remains on the applicant to be as specific and clear as possible.

Review committees are generally composed of a multidisciplinary mix of funded researchers, often also including lay representation. The officer representing the agency will be responsible for the committee membership, for assigning the reviews to committee members, for assuring that the committee adheres to review protocols, and for communicating the results of the review to relevant departments, the investigator, and the investigator's institution. If, in the opinion of the officer, appropriate expertise to review a particular proposal is unavailable within the committee, then external reviews can be obtained. These reviewers might or might not be involved in subsequent committee discussion: Some agencies use their written reports only, other involve them with a telephone link, and, occasionally, this person is brought into the review committee discussion as an ad hoc member to present the 
proposal as first or second reviewer so that, should questions arise, important issues can be clarified. The role of such experts on the committee, and whether they are voting members, has important ramifications for the final funding decision.

\section{EVALUATING THE QUALITATIVE PROPOSAL}

Excellent qualitative inquiry is a leap into the unknown. This does not mean, however, that the researcher is asking for a blank check from the funding agency-a great deal of thought and preparation will have been conducted in the process of preparing the proposal. It does mean that enough differences are evident in a qualitative proposal that it is invalid and unfair to use quantitative criteria for evaluating qualitative applications.

When evaluating a qualitative proposal, the review committee must place the greatest weight on the idea proposed and on the abilities of the investigator, viewing the remaining features of the proposal as supporting evidence of investigator competence and project feasibility. The uncertain, exploratory course of qualitative inquiry demands that the research design be flexible and the investigator responsive to the emerging findings. Thus, to a certain degree, the investigator is thoughtfully creating or recreating the design as the study proceeds. Within this context, I will discuss the components of scientific review for qualitative applications.

The criteria proposed herein are based on three dimensions: relevance, rigor, and feasibility (see Guba, 1981). Relevance refers to the potential contribution of the research-the worthiness of the research question and the potential contribution of the results to the discipline and to social science in general. Rigor refers to the adequacy and appropriateness of the method to address the questions proposed and solidity of the research design. Feasibility refers to the ability of the researcher to conduct the research, the resources available and requested (including the time assigned for the project), and evidence of access to the setting and participants, including ethical concerns for protecting the rights of human subjects. In other words, feasibility refers to the probability that the project will be completed as described. Each of these dimensions is discussed below in the context of eight components of a proposal, listed in Table 1.

\section{The Research Problem or Question}

Assessing the relevance of the research question is the first and most important component for evaluation; if answering the research question will not add to the literature, then the study is not worth funding. The onus is on the investigator to convince the reviewers that the project is vital for the advancement of their disciplinary goals. Thus, proposal writing, although objective, balanced, and realistic, is also a political endeavor.

A fascinating topic? Ideally, the qualitative proposal should, to use Glaser's (1978) term, "grab" everyone's attention. It must intrigue even those reviewers who are from another discipline, who have little knowledge of the area, and who are not familiar with the disciplinary focus, assumptions, and theoretical needs that this proposal will address. 
TABLE 1: Dimensions of Evaluation Criteria According to Components of the Proposal

\begin{tabular}{|c|c|c|c|}
\hline \multirow[b]{2}{*}{ Component of the Proposal } & \multicolumn{3}{|c|}{ Dimension of Evaluation Criteria } \\
\hline & Relevance & Rigor & Feasibility \\
\hline 1. Problem/question & $\begin{array}{l}\text { A fascinating topic? } \\
\text { Important to substantive area? } \\
\text { Significant contribution to discipline topic } \\
\text { and practice? }\end{array}$ & $\begin{array}{l}\text { Literature review comprehensive? Synthesized? } \\
\quad \text { Philosophical framework identified? } \\
\text { Analysis of concepts and theories? } \\
\text { Use of a theoretical context? } \\
\text { Use of a skeletal framework or a scaffold? }\end{array}$ & $\begin{array}{l}\text { Doable? } \\
\text { Appropriate scope? }\end{array}$ \\
\hline 2. Investigator capability & $\begin{array}{l}\text { Legitimacy: } \\
\text { Able to evaluate field? } \\
\text { Able to recognize new knowledge? } \\
\text { Able to distinguish between the norma- } \\
\text { tive and the extraordinary }\end{array}$ & $\begin{array}{l}\text { Skill: } \\
\text { Necessary experience with methods? } \\
\text { Versatile and knowledgeable? } \\
\text { Able to practice reflexivity? }\end{array}$ & $\begin{array}{l}\text { Competence: } \\
\text { Necessary professional qualifications for } \\
\text { access? } \\
\text { Adequate qualifications and experience with } \\
\text { methods? (Adequate track record) } \\
\text { Personal characteristics for fieldwork? }\end{array}$ \\
\hline 3. Proposed methods & $\begin{array}{l}\text { Pertinent/relevant to phenomenon? } \\
\text { Theoretical drive? }\end{array}$ & $\begin{array}{l}\text { Appropriate to question and research goal? } \\
\text { Adequately described? Evidence of adhering to } \\
\text { methodological assumptions? } \\
\text { Flexibility evident? }\end{array}$ & $\begin{array}{l}\text { Doable? Acceptable to participants? Appropriate } \\
\text { to context? }\end{array}$ \\
\hline $\begin{array}{l}\text { 4. Selection of research } \\
\text { context }\end{array}$ & $\begin{array}{l}\text { Participants will provide information? } \\
\text { (Maximize bias) } \\
\text { Relevant to problem? } \\
\text { (Theoretically selected) } \\
\text { Relevant to question? }\end{array}$ & $\begin{array}{l}\text { Appropriate? Maximizes phenomenon? } \\
\text { Adequate for saturation? } \\
\text { Sample theoretically driven? }\end{array}$ & $\begin{array}{l}\text { Participants feasible and accessible? } \\
\text { Context receptive? }\end{array}$ \\
\hline 5. Design & $\begin{array}{l}\text { Methods/strategies current and well } \\
\text { justified? }\end{array}$ & $\begin{array}{l}\text { When appropriate, permits comparison? } \\
\quad \text { Exploration over time? } \\
\text { Degree of abstraction/level of explanation } \\
\text { sought? } \\
\text { Multiple/mixed method design? }\end{array}$ & Reconsider scope of inquiry \\
\hline 6. Analytic plans & $\begin{array}{l}\text { Methods will produce results in necessary } \\
\quad \text { form? } \\
\text { Adequate outcome? } \\
\text { Plans for transference/application/ } \\
\quad \text { generalizability }\end{array}$ & Proposed use of prior knowledge appropriate? & Informed/experienced investigator team? \\
\hline
\end{tabular}


7. Time/duration of project

8. Budget

9. Human subjects

10. Dissemination/ application

11. Anticipated product: Usefulness

Fit to existing knowl-

Usefulness
Consider the stability of the phenomena studied: Will it be changed/dissipated by the time the researcher reaches this point? (e.g., the aftermath of a disaster)

Appropriate allowance for reciprocity? Allowance for dissemination/application of results?

As proposed, no participant violations?

Plans practical? edge and praxis
Time adequate for getting close to participants? Eliciting quality data?

Flexibility in design?

Reflection during analysis?

Returning to the literature?

Developing results theoretically?

Adequate considering the complexity of the project?

Feasible design as proposed? (If not feasible as proposed, will modifications affect rigor?)

Plans outlined?

Quality
Reconsider adequacy of investigator time commitment-project doable?

Adequate time for "getting in"?

For saturating data?

For conceptualizing?

For writing?

For contingencies?

Adequate staff? Appropriately trained and

experienced?

Adequate resources to complete project?

Feasible setting? Permissions? Participant safety? Researcher safety?

Plans for dissemination and application doable?

Applicability

NOTE: Dimensions of evaluation criteria are derived from Guba (1981). 
Important to substantive area? Substantive areas are interesting. Although they often cross disciplinary boundaries, topics may be better developed or refined, or used differently in different disciplines. For example, concepts such as trust or social support are used broadly in the health sciences, family studies, business, education, and so forth, but are used and emphasized differently in the various disciplinary contexts. This is both a blessing and a curse. It is problematic for the applicant, for it means that the literature review cannot be limited to one discipline, but it is also a blessing, as it gives the research much more impact, making the study more attractive to the committee members, who can then see the relevance of the question asked in their own discipline. Reviewers will ask whether the present study will contribute to knowledge of the topic in general or the author has limited the study to a particular context, problem, or discipline. It is important that the applicant demonstrate an awareness of the broad significance of the question.

Significant contribution to discipline topic and practice? Contrary to Glaser's (1978, 1992) recommendations, excellent researchers should explore the literature broadly at the planning stage, for to be funded, the proposal must be logically, accurately, pragmatically, and profoundly argued. The literature review should take the form of an argument addressing the need to answer the question. To do that, the literature review must be complete and comprehensive, it must be a theoretical/conceptual analysis, and it must place the present study in theoretical context of the literature.

Evaluating the literature review. In light of this, affecting the rigor of the proposed research, the literature review must be comprehensive, addressing all relevant studies. The applicant must have synthesized the material so that it is a "good read." Some applicants submit tables listing all relevant studies, and this is a useful method to inform the committee that you have done your homework, are familiar with the literature, and are confident in your claims. The analysis of the literature should include analysis of the relevant concepts and theories, and an excellent critical analysis of these concepts and theories might be publishable, constituting a contribution in its own right.

A conceptual framework, dictating which variables will be examined, or even coded, is usually not used in qualitative inquiry as it violates principles of induction, hence threatening validity (Huberman \& Miles, 1994). Theoretical frameworks should not be used to the extent that they influence the research design deductively. For instance, they must not provide a coding scheme that will presort data or overly constrict observations. If the applicant has enough knowledge to develop a detailed theoretical framework, then he or she should not be using qualitative methods but, rather, should be testing the framework using quantitative inquiry. On the other hand, as with most phenomena, some findings reported in other studies are certain and need not be investigated again without compromising rigor, and there are several useful strategies that can be used to target inquiry without violating principles of induction. These include identifying the philosophical underpinnings, placing the research into a theoretical context, or working from a skeletal framework or scaffold (see Morse \& Mitcham, 2002).

Philosophical underpinnings identified? It is important that if philosophical underpinnings are used, they must be made explicit. The researcher often has a philosophical perspective, such as feminist inquiry or critical theory, and, if used, this 
must be explained. Often, these perspectives have been integrated into the methods, such as critical ethnography (Reason, 1994) or feminist grounded theory (Wuest \& Merritt-Gray, 2001), but this is not always the case. The point is that if used, these ways of viewing data must be described in the proposal.

Use of a theoretical context. The theoretical context is an argument that places your study in the broader context of the literature. It illustrates the importance or contribution that knowing more about a particular topic will make to the discipline or to knowledge in general. Consider an example: At one time, I wanted to explore the gifts that patients gave nursing staff (Morse, 1991b). Something important was happening, because these gifts continued despite the ruling of hospital administrators to prevent staff from accepting gifts and for them to redirect these gifts to hospital foundations. However, when I presented a proposal to study gift giving, the committee considered the topic trite (and even an embarrassment for an agency to be funding a behavior that was not supposed to be happening), and the proposal was denied. However, when I considered why these gifts were continuing, I could identify a theoretical rationale for the study, which provided significance-and a reason for the committee to fund the study. I added a theoretical context, arguing that nurses "gave" care to the patients yet were reimbursed by the hospital (as salary). This imbalance left the patient indebted to the nurses and in a position of dependency-which might even inhibit recovery or lead to depression. Reciprocating for care was an essential part of the nurse-patient relationship, and therefore it was important to understand the function of gift giving.

Now, you will observe that I was not studying recovery or depression. I was also not studying what would have happened if gifts were intercepted or not given. I argued that the first step was to explore the phenomenon itself-but presenting the problem within a theoretical context allowed the granting agency to appreciate the practical significance of the problem.

When qualitative researchers are planning to investigate relatively new areas or concepts that are relatively immature, must inquiry always begin presuppositionless? If, to ensure rigor, qualitative inquiry always began from the beginning, we would not get very far-of course, knowledge builds incrementally, and, in some areas, concepts might be at least partially mature, making the reinvention of the wheel unnecessary. Two strategies are available to qualitative researchers to enable them to maintain an inductive thrust while standing on previously conducted research, thereby maintaining rigor. The first is a skeletal framework. In this case, the researcher might be able to identify the characteristics or attributes of the concept of interest, but these need to the "fleshed out." There is a need, for instance, to obtain much more data about the conditions, circumstances, variations, and interrelationships of the characteristics that surround the structure, to build theory. The second strategy is to use the information from previous studies as a scaffold and to use the known information to bound or surround the concepts while inductively filling in the detailed characteristics within a particular context, before moving on, as the analysis proceeds and theory is built, to decontextualize the analy- sis (Morse, Hupcey, et al., 2002). The important point is that the applicant must describe to the committee how a priori knowledge will be used in the design, how validity will not be compromised, and how the research will fit into or contribute to what is already known.

Finally, an excellent literature review funnels the reader from the general to the specific, so that by the time the review committee reaches the questions or problem 
statement, it has been sold on the idea itself (Morse \& Richards, 2002). This does not mean that the qualitative researcher selectively ignores information that does not help build the case; rather, such information is countered in the argument. The argument then ends with a convincingly significant and clearly stated problem statement or question.

The feasibility of the problem or question is evaluated by considering if the proposal is doable. Does it have an appropriate scope? Projects that are designed too broadly will take too long to achieve any degree of depth and to saturate data, and will become unmanageable; projects that are defined by a question that is too narrow will not answer the question adequately. The evaluation of the feasibility of a question is challenging but must be addressed by the investigator.

Occasionally, qualitative research is contentious because it threatens to undermine the status quo. Sometimes, entire research careers have been built on the very concepts that the qualitative applicant is proposing to reopen. Again, the applicant must be able to produce adequate evidence that the present conceptualization is suspect, possibly flawed, and worthy of reexamination, even though it has been defined consistently in a certain way. Committees generally have mechanisms for committee members who would be in conflict with such an application to withdraw from the discussion of the proposals. However, it is these proposals (and subsequent publications) that instigate corrections and paradigm shifts and might prove to be a risk well worth taking for the committee. One such example is the work by Hupcey (1998) reconceptualizing social support.

Infrequently, a proposal addressing an area about which little is has been written will be presented to the committee. In health care, for instance, we have many phenomena for which we have no language and little knowledge, yet exploration of these topics is important. Often, these areas have been unexplored because of the emotional cost to the investigator, and it is easier for the caregiver not to know. How do patients maintain control during states of agony? How do surgeons learn to cut through skin? How do we control or block the effects of the excruciating pain of a patient or control the contagion of suffering? Investigation must start somewhere. In these cases, the committee must consciously support the investigator and the idea, rather than the mechanics of the research design, and the applicant must provide the committee with enough information to support the proposal with the confidence that the investigator is skilled enough to achieve the proposed goals.

Quite frequently, agencies will publish guidelines for proposals presenting outlines requiring components that are inappropriate for qualitative designs, such as hypotheses. ${ }^{8}$ In qualitative inquiry, the researcher does not have adequate information to develop conjectures, or perhaps even to articulate a question clearly. When confronted by one of these guidelines, researchers should explain in detail within the proposal why hypotheses are not presented. In addition, it is appropriate to contact the agency and discuss how the issue should be approached in the proposal.

\section{Investigator Capability}

For major funding, principal investigators must present evidence of adequate experience as a qualitative researcher and demonstrate that the team is creative and capable of completing the project with excellence. 
Investigator legitimacy. There is an insider/outsider debate in qualitative inquiry: Should the researchers be members of the cultural or occupational group that they are studying, or should they be outsiders, previously unconnected with the participants? There are merits to both relationships. If the researchers are, for instance, teachers studying teachers, or nurses studying nurses, the occupational license provides them with instant credibility. They have knowledge of the literature and are, therefore, easily accepted as a legitimate authority to evaluate the setting. They are able to understand (and therefore do not question) many of the behaviors observed and can distinguish between the normative and the extraordinary. The topics they are likely to study are considered to be relevant to the discipline and the results of their research applicable. On the other hand, if the researchers are not members of the cultural or occupational group, they are more likely to see the hidden assumptions within the group they are studying and be able to identify knowledge that would otherwise be implicit. Their data collection and analysis phases are likely to move more quickly, and their research agenda and analysis are not bound by disciplinary agendas. Therefore, although those who have disciplinary qualifications might be considered more legitimate in data collection, both insiders and outsiders have to earn researcher legitimacy in the process of gaining entry. However, the quality and nature of data collection by those who have similar disciplinary affiliation and those researchers who are not familiar with the setting will differ according to perceived investigator legitimacy.

Investigator skill. The principal investigator (PI) must be well published in previous research using the methods proposed in the present application, theory smart, and knowledgeable in methodological issues. Previous research should be creative and have made an impact on the discipline - and even beyond - for the best predictor of future success in an application is evidence of capability. If investigators are productive and making an important contribution, then clearly their funding should continue, provided the ideas proposed continue to appear interesting and worthy of investigation.

Ideally, the PI should be versatile, adept in the use of several qualitative methods, especially if the topic proposed is complex. Methodological versatility will enable the researcher to select the right methods to use with the right data and to get the type of results needed, thus contributing to project rigor. If the PI is well versed in only a single method, then the reviewer should evaluate the research team: Do the coinvestigators have complementary skills? Is there evidence in the proposal that the investigator will seek consultation rather than backing off from exploring a difficult phenomenon or trying to force phenomena to fit an incompatible research approach? Consider this example: A professor proposes a phenomenological study, but it is clear to the committee that an observational component would greatly expedite the research. Would this applicant or research team be capable of conducting the observational component should it be necessary? Have they identified consultants to assist with this component?

Investigator competence. How can the abilities of the PI and research team be evaluated to ensure the agency that the research is feasible? Does the team have the necessary professional qualifications for assessing the setting? Do the team members have previous experience with the methods proposed? The curriculum vitae ("biosheet") of each member of the research team should reveal productivity in the 
form of previously funded research grants (preferably as PI) and publications in peer-reviewed journals. Some review committees, particularly those offering salary only, training, or career awards, also check citation indexes to ascertain the impact of the research on the discipline. In the section describing investigators, prior work conducted by the team should be described, as well as members' abilities clearly outlined. Evaluate the team as a whole: If there are any apparent gaps, have consultants been identified, and have their biographical details and "agreement to serve" letters been included in the application?

For small grants, if the investigator is a pre- or postdoctoral student or a junior researcher, the qualifications of the student's advisor or the consultants on the project become very significant. In these cases, the qualifications of the consultants, the amount of time they will contribute to the project, their relationship with the PI, and mode and frequency of contact are evaluated.

\section{Proposed Methods}

The relevance of the fit of the method to the problem must be assessed. Overall, the methods must be logically linked to the topic. Different methods require different types of data, so the method(s) selected must best be able to provide the information needed to explore the proposed question or problem statement and also provide the solution. Basically, some qualitative methods best elicit meaning (phenomenology), some give insights into processes (grounded theory), and some analyze everyday life (ethnography). Some provide a particular frame (observational methods), which can be microanalytic (video analyses) or macroanalytic (participant observation). Methodological congruence must also be evident.

Appropriate to method and goal? Critical to the assessment of rigor, whatever methods are selected must be justified. If more than one method is proposed, then the research design must also be justified. In addition to a comprehensive description of the methods as they will be used in the particular context, how these methods fit together must be explained in the proposal if some type of triangulated or multimethod design is planned. When a mixed-method design is proposed, wherein each method is complete in itself and the results triangulated, the pacing and theoretical drive of the qualitative and quantitative components must be explained.

In multi- and mixed-method designs, evidence of adhering to the methodological assumptions for each method is essential. In particular, attention must be paid to sampling and to the style of interviewing, so that appropriate data for each method are available.

Implicit in single-group qualitative designs is comparison with the literature or the researcher's own experience. Qualitative researchers may move analytically by developing conceptualization, by moving data over conceptual templates; alternatively, comparison groups facilitate the process of identifying characteristics of interest. Such issues of design and strategies for analysis must be explicated.

\section{Selection of Research Context}

The criterion of relevance is most important when considering the research context. In qualitative inquiry, the setting, participants, and situation must be selected so 
that the opportunity to observe the phenomenon of interest is maximized. It must be most relevant to the problem. Qualitative researchers seek bias and use bias, so that they are exploring the best examples of the characteristics of whatever they are studying. This principle is consistent with the principles of science: Consider it equivalent to a chemist's using only pure, uncontaminated samples when analyzing a substance. Therefore, the review committee should consider whether the setting will optimally allow observations of the phenomena of interest, if the participants selected will be the best example (no, not the average!) of the experience, and if the events selected are the most representative of the phenomenon rather than demographically representative of the population. Of course, the rationale to convince the committee should have been provided by the applicant.

Because the researcher cannot predict how long it will take to identify characteristics or themes and to begin developing theory, or how much data will be required, he or she can give only approximations of sample size. However, as the amount of data required has a profound impact on the budget, we will revisit this issue again in the Budget section.

Finally, the people who make up the sample must be accessible and cooperative toward the project. If applicable, a letter from the site where the study will take place, stating that they are willing to cooperate with the research team, should be included in the research proposal as evidence of feasibility.

\section{Design}

Relevance of the proposed design is considered by determining if the proposed methods and strategies are well justified and will enable the research questions to be answered. There should be a fit between the purpose, research question, and methods used so that the research design will optimize the chance of both answering the research questions and providing the type of results necessary.

Rigor is evaluated according to how well the proposal meets methodological standards for qualitative inquiry. Does the proposal describe how the interviews and observations will be conducted? What other data will be sought for analysis? One of the problems in reviewing the proposal is the researcher's uncertainty about the course of the inquiry: Is the researcher aware of unanticipated findings and open, responsive, and flexible about incorporating unexpected findings into the design? Will the design permit comparisons, longitudinal exploration of phenomena, and so forth?

Overall, even if quantitative components are introduced into the project, the project should be qualitatively driven. For instance, if a sequential QUAL $\rightarrow$ QUAN design is used (Morse, 2003), with an initial descriptive phase consisting of interviews and a Likert-like scale developed from these interviews that is subsequently quantitatively validated and administered to a large, randomly selected sample, then the overall thrust of the project will be based on inductive approaches (Morse, 2003). Awareness of the major thrust of inquiry, and the fact that the investigator must at any particular phase adhere to the principles of qualitative or quantitative design, are important aspects of maintaining rigor.

The scope of inquiry should be considered in light of the design, again to assess feasibility. The proposed components of multimethod or mixed design to obtain perspectives of the phenomenon, the level of abstraction or theory sought, and the skill 
and abilities of the investigator should also be evaluated to determine whether the project remains practical and possible.

\section{Analytic Plans}

Relevance considers if the analytic plans will produce results in the necessary form. If a descriptive study is planned, is that the level of data that will answer the research questions? If focus groups are used, will the opinions, presented as snippet data, produce the degree of certainty and depth necessary to answer the research question? Again, a good fit between purpose and outcomes is essential: Are plans developed for the transference, application, and generalizability of findings?

Issues of rigor include how data will be coded and analyzed, congruent with the method proposed. If computer software is used, is the investigator skilled in its use and aware of its limitations? Does the investigator have plans for the verification of data? How will the emerging categories and themes be evaluated for saturation? What level of explanation/abstraction will be sought? How will concepts be developed and theory constructed?

The feasibility of a project can be demonstrated by conducting a small project to determine if the project can be carried out-is acceptable to participants, to train staff, and so forth. These projects do not require findings and tend to increase reviewers' confidence in the project. In qualitative inquiry, a pilot study is generally considered inappropriate (Morse, 1997). The main problem is that to make sense, data analysis in qualitative inquiry is reliant on saturation. When saturation is not reached (as in the case of the small samples used in pilot studies), the analysis might not make sense, might be misleading, or might simply be wrong. These analyses are actually more difficult to conduct, as with inadequate data, the categories or themes might not be evident. Should the pilot continue until a meaningful analytic scheme is obtained, the researcher might as well continue and finish the study (Brink, 1990). Some investigators conduct "pilot" work to see if they have access to a setting, but getting in takes time-in particular, time before meaningful data are collected-and this period is actually a phase of the study. Learning to use equipment is not pilot work but training, as is learning to conduct interviews or learning to use software.

\section{Time Line/Duration of the Project}

The reviewer should ensure that the researchers have allowed for adequate time to do the study. Have they allowed time to get in, time to earn the trust of participants, adequate time to collect data, time to think, time to analyze and verify, time to conceptualize, and time to write and prepare publications and to disseminate? To be successful, qualitative researchers cannot calculate the time required for a project using simple math with the projected number of interviews, and one of the most common problems is not enough time. In fact, qualitative researchers complain that the 3-year period often allocated in grant cycles is not long enough to complete a project. Inadequate time, clearly, will kill a project or result in a project that has not become all it could—and should—be.

Considering this, review committees should assess the amount of time the PI has allocated to the project as well as concurrent projects and responsibilities, along with the adequacy of the team and the duration of the grant. 
Equipment and facilities. As previously mentioned, qualitative inquiry as a research endeavor can no longer be conducted from the PI's office. Ideally, a qualitative laboratory should be available with the space to work/collaborate with the team. Are the necessary computers available or requested? Are cameras and other necessary equipment available? Is the necessary technical assistance available? These aspects are considered for every grant, but not until recently has the need for such space been recognized as essential for qualitative inquiry.

\section{Budget}

If qualitative inquiry is to be good, it is expensive. Collecting interview data, transcribing it, and analyzing the text are slow and time consuming. Investigators may use "rules of thumb" when estimating their budget. For instance, transcription usually takes 4 times as long as the recording (or 8 times if the transcript is being prepared for conversational analysis), and these calculations should be presented in the budget.

The quandary of "How many subjects?" and "How much data?" can only be approximated at the proposal stage but, realistically, for purposes of determining the budget, needs to be estimated. Qualitative researchers calculate the proposed sample size by evaluating the scope of the project and the expected variation in data, the duration of data collection (one-time versus longitudinal design), and the number of participants used in other studies to reach saturation, plus a contingency allowance for interviews lost through equipment failure, poor participants, and possible expansion into unanticipated areas of interest.

Should budgets that appear excessive be cut back in committee? I cannot advise on this matter, for each case must be considered on its own merits. However, once again, personnel costs on qualitative proposals will necessarily be high.

\section{Human Subjects}

The final part of the review is to ensure that the rights of human subjects have been protected. This usually ensures that the risks of participating in the research are not greater than those of everyday life, that participants are informed and consent to participating in the research, and that they have the opportunity to withdraw from the research. University committees, as well as review committees responsible for the site hosting the study, provide written certification with the proposal that they have reviewed and approved of the study prior to the release of funds. Nevertheless, it is the responsibility of the review committee to also review the proposal for ethical concerns. These issues, if concerns are raised, will prevent the study from going ahead and interfere with its feasibility.

Qualitative inquiry is usually considered low risk. However, investigators must take precautions to protect the identity of participants or, if identities are revealed (as in video research), to ensure that the participants are aware and have provided additional consent for the tapes to be shown publicly. Both committees and researchers must be aware that following qualitative traditions of publishing participants' quotations in the text of manuscripts (with links to individuals) thereby protects anonymity (Corbin \& Morse, 2003). Protecting to ensure anonymity, depending on the nature and extent of the changes, can interfere with rigor (see Davis, 1991). 


\section{Dissemination/Application}

Dissemination might be beyond the scope of an individual project but be a part of the overall research program. If included, relevance of the dissemination plans is considered excellent if they appear to target the practitioners concerned and are practical. They are considered rigorous if there is a good fit between the type of results and the plans, and feasible if they do not impose prohibitive costs, including staff time.

\section{Anticipated Product: Fit to Existing Knowledge and Praxis}

To achieve relevance, the results must be useful; to achieve rigor, they must be of high qualitative; to achieve feasibility, they must be applicable. Minimally, there must be a fit between the qualitatively derived knowledge and praxis, and this linkage should be described.

\section{SCORING, RANKING, AND APPROVING THE PROPOSAL}

Once the proposal has been presented, questions answered, and concerns discussed by the committee, the proposal is scored. The mean score derived from all committee members determines the ranking of the proposal within all the proposals reviewed by that group and whether the proposal is approved for funding.

\section{RECOGNIZING THE UNCERTAINTY IN FUNDING QUALITATIVE INQUIRY}

I began this article by outlining the difficulties for agencies in funding research that was not contractual - that had an uncertain course and poorly defined outcomes. Although all research is, to some extent, a process of discovery, this is maximized with qualitative inquiry. Two ways to prevent unpleasant surprises at the final report stage are for the agency to request annual reports and for the investigator to contact the agency if major decisions are made that substantially alter the course of the project.

Sometimes, qualitative researchers report that they asked the wrong research question originally and during inquiry had to rethink and rephrase the original question. Although such information makes a funding agency uneasy, it is essential for the validity of the final study. For instance, Norris (1991), while exploring the experience of mothers consenting to their adolescent daughters' abortions, came to realize in the course of the study that the abortion itself was part of a larger process of protecting their daughters from pregnancy. To delineate the emerging analysis with the single event of "consenting for the abortion" would have truncated the results and made the findings less rich and less significant. Thus, committees must recognize that occasionally, the expected outcomes from a funded study will not be exactly what they get. The onus is on the investigator to communicate frequently with the research staff at the agency and to keep them informed with regular progress reports. ${ }^{9}$ 


\section{REAPPLICATION}

Applicants whose proposals are not funded may decide to reapply for funding in the following review cycle. Funding guidelines usually provide further directions for such reapplication, for instance, requesting that the applicant respond to the reviewers' comments in an additional page and highlight all changes within the body of the proposal.

In cases of reapplication, the investigator might choose to respond by altering the research strategies or design, by adding or modifying components to correct deficiencies, or by tactfully rebutting the committee's criticisms. Such strategies should, theoretically, guarantee a perfect score on reapplication. However, there is no assurance that the same reviewers will not change their minds, have additional insights, or discover further flaws, or that the proposal will be reviewed by the same reviewers, by the same committee membership, or even by the same committee. Although theoretically, persistence should be rewarded by the eventual funding of the project, this cannot be assured. Agencies should be accountable for their decisions and have an appeal process in place, but this is not always the case either. ${ }^{10}$

Researchers should be aware that the researcher who is not funded might have a hidden and unknown cost to society, as does research that is funded and is of no or little use. Committees might make correct and wise decisions in rejecting your proposal, but sometimes they do make incorrect decisions. Researchers who are denied funding must make decisions about reapplying: Is it faster to obtain funding by reapplying to the same agency or by submitting elsewhere? Is it a matter of rewriting the proposal to educate the committee or of revising the design? I am very aware that having a proposal denied is very costly in lost time-which can delay a research program by years (Morse, 1992).

Perhaps it is necessary to lobby for changes within the agencies-a slow and painful mechanism to receive funding and one with personal costs, for time spent lobbying should be time spent doing research. This is a task for us all to do collectively and systematically, for it involves changes such as broadening research priorities and perspective on what is considered researchable and what constitutes research. It involves political problems, such as expanding and sharing research funds to new groups of investigators. In this light, the administrative changes involved, such as developing appropriate review criteria, expanding committee membership, and educating other scientists about the principles of qualitative inquiry, as discussed in this article, appear trivial.

\section{SUMMARY}

The successful funding of a qualitative proposal should be weighed according to the qualities of the investigator, the idea, and the proposed approach to analyzing the problem. The committee considering the proposal must be convinced that the investigator is competent, that the idea is worthy of funding, and that the methods will enable the investigator to address the problem. In addition, reviewers are concerned with ethics-that no harm will result from the research (or that the research is a justified risk). 
It is the responsibility of the applicant to prepare a persuasive yet balanced, comprehensive application within the parameters of the agency's guidelines. It is the responsibility of the agency to provide a competent, valid, and fair review. Agencies must recognize that if review guidelines are specific, then they will not be usable for all types of research; if review guidelines are general, then the committee must provide a fair and balanced mix of expertise within the review committee membership to provide the necessary review.

The guidelines recommended in this article are for use by those in the latter group. They are designed as questions to aid in focusing the review by committee members with qualitative expertise and to assist the researcher in presenting the proposal to the committee. They are abstract enough to be used for a variety of qualitative methods to construct a comprehensive, accurate, and fair review.

\section{NOTES}

1. Although this article is written primarily for reviewers, it might also be useful for applicants. In addition, some advice is already available for applicants on preparing proposals (see Cohen , Knafl, \& Dzurec, 1993; Connelly \& Yoder, 2000; Office of Behavioral and Social Sciences Research, 2001; TrippReimer \& Cohen, 1991), and examples of qualitative proposals have been published elsewhere (see Morse, 1996; Tripp-Reimer, 1986).

2. The amount of qualitative expertise varies by committee and by agency, as does the methodological emphasis of knowledge of type of qualitative expertise.

3. National Institutes of Health (NIH) voting conventions require that members declare if their score is outside the range recommended by the primary reviewers prior to voting. This ensures that the information is available in the reviews/critique of the proposal and matches the score.

4. As described later in the article, a large part of the responsibility for funding is on the assigned effectiveness in conveying the value of the research to other committee members.

5. For a discussion of multiple- and mixed-methods design, see Morse (2003).

6. Published examples of committee reports were available formerly (see Morse, 1996; TrippReimer, 1986), but recently, agencies have not been releasing these reports for publication.

7. A good reviewer must also be skilled and articulate to present the argument supporting or critiquing the proposal to the committee, be a member of the team, and listen to and work with other committee members.

8. An example of requesting hypotheses is the US PHS 398 form. The recent document published by the Office of Behavioral and Social Sciences Research (2001) acknowledges that qualitative researchers "ask broad, open-ended questions" (p. 2).

9. Although the source of external funding might inherently influence findings, it is important that the agency be acknowledged in all presentations and communications, as well as to the participants (Cheek, 2000).

10. For example, the Canadian Institutes of Health Research (CIHR) does not, at this time, have an appeal process; the NIH does.

\section{REFERENCES}

Brink, P. J. (1990). Dialogue: The granting game. In J. M. Morse (Ed.), Qualitative nursing research: A contemporary dialogue. Newbury Park, CA: Sage.

Cheek, J. (2000). An untold story? Doing funded qualitative research. In N. K. Denzin \& Y. S. Lincoln (Eds.), Handbook of qualitative research (2nd ed., pp. 401-420). Thousand Oaks, CA: Sage.

Cohen, M. Z., Knafl, K., \& Dzurec, L. C. (1993). Grant writing for qualitative research. Image: Journal of Nursing Scholarship, 25(2), 151-156.

Connelly, L., \& Yoder, L. H. (2000). Improving qualitative proposals: Common problem areas. Clinical Nurse Specialist, 14(2), 69-74. 
Corbin, J., \& Morse, J. M. (2003). The unstructured interactive interview: Issues of reciprocity and risks when dealing with sensitive topics. Qualitative Inquiry, 9(3), 335-354.

Davis, D. S. (1991). Rich cases: Ethics of thick description. Hastings Center Report, 21(4), 12-17.

Glaser, B. G. (1978). Theoretical sensitivity. Mill Valley, CA: Sociology Press.

Glaser, B. G. (1992). Basics of grounded theory analysis. Mill Valley, CA: Sociology Press.

Guba, E. G. (1981). Criteria for assessing the trustworthiness of naturalistic inquiries. Educational Communications and Technology Journal, 29(2), 75-91.

Huberman, A. M., \& Miles, M. B. (1994). Data management and analysis methods. In N. K. Denzin \& Y. S. Lincoln (Eds.), Handbook of qualitative research (pp. 428-444). Thousand Oaks, CA: Sage.

Hupcey, J. (1998). Clarifying the social support theory-research linkage. Journal of Advanced Nursing, 27, $1231-1241$.

Morse, J. M. (1991a). On funding qualitative proposals [Editorial]. Qualitative Health Research, 192, 147151.

Morse, J. M. (1991b). The structure and function of gift-giving in the patient-nurse relationship. Western Journal of Nursing Research, 13, 597-615.

Morse, J. M. (1992). The myth of the programmatic research grant. Canadian Journal of Nursing Research, $24(2), 15-25$.

Morse, J. M. (1996). The qualitative proposal. In J. M. Morse \& P. A. Field (Eds.), Nursing research: The application of qualitative approaches (pp. 160-196). Cheltenham, UK: Stanley Thornes.

Morse, J. M. (1997). The pertinence of pilot studies [Editorial]. Qualitative Health Research, 7, 323-324.

Morse, J. M. (2002). Myth \#53: Qualitative research is cheap [Editorial]. Qualitative Health Research, 12, $1307-1308$.

Morse, J. M. (2003). Principles of mixed and multi-method method research design. In A. Tashakkori \& C. Teddlie (Eds.), Handbook of mixed method (pp. 189-208). Thousand Oaks, CA: Sage.

Morse, J. M., Hupcey, J., Penrod, J. A., Spiers, J., Pooler, C., \& Mitcham, C. (2002). Issues of validity: Behavioral concepts, their derivation and interpretation. International Journal of Qualitative Methods, 1(4), Article 3. Retrieved Dec 17, 2002, from http://www.ualberta.ca/ ijqm

Morse, J. M., \& Mitcham, C. (2002) Exploring qualitatively-derived concepts: Inductive-deductive pitfalls. International Journal of Qualitative Methods, 1(4), Article 3. Retrieved Dec 17, 2002, from http:// www.ualberta.ca/ ijqm

Morse, J. M., \& Richards, L. (2002). Readme first for a reader's guide to qualitative methods. Thousand Oaks, CA: Sage.

Munhall, P. L. (2001). Institutional review of qualitative research proposals: A task of no small consequence. In P. L. Munhall (Ed.), Nursing research: A qualitative perspective (3rd ed., pp. 551-564). Sudbury, MA: Jones \& Bartlett.

Norris, J. (1991). Mothers' involvement with their adolescent daughters' abortions. In J. M. Morse \& J. L. Johnson (Eds.), The illness experience: Dimensions of suffering (pp. 210-236). Newbury Park, CA: Sage.

Office of Behavioral and Social Sciences Research. (2001). Qualitative methods in health research: Opportunities and considerations in application and review (NIH Publication No. 02-5040). Washington, DC: National Institutes of Health.

Reason, P. (1994). Three approaches to participative inquiry. In Y. Lincoln \& N. Denzin (Eds.), Handbook of qualitative inquiry (pp. 324-339). Thousand Oaks, CA: Sage.

Tripp-Reimer, T. (1986). The Heritage Health Project: A research proposal submitted to the Division of Nursing. Western Journal of Nursing Research, 8, 207-228.

Tripp-Reimer, T., \& Cohen, M. Z. (1991). Funding strategies for qualitative research. In J. Morse (Ed.), Qualitative nursing research: A contemporary dialogue (pp. 243-256). Newbury Park, CA: Sage.

Wuest, J., \& Merritt-Gray, M. (2001). Feminist grounded theory revisited: Practical issues and new understandings. In R. S. Schreiber \& P. N. Stern (Eds.), Using grounded theory in nursing (pp. 159-176). New York: Springer.

Janice M. Morse, Ph.D.(Nurs.), Ph.D.(Anthro.), D.Nurs.(Hon.), F.A.A.N., is scientific director of the International Institute for Qualitative Methodology, a professor of nursing at the University of Alberta, Edmonton, Canada, and editor of Qualitative Health Research. 